\title{
LETTER
}

\section{Heart rate variability analysis and weaning from mechanical ventilation: lessons from exercise physiology}

\author{
Andry Van de Louw
}

See related research by Huang et al., http://ccforum.com/content/18/1/R21

In the previous issue of Critical Care, I read with interest the article by Huang and colleagues, who suggested that heart rate variability (HRV) changes might predict the success of ventilator weaning [1]. Although this perspective is attractive, a methodological issue must be highlighted.

The fast Fourier transform, as used by the authors to assess HRV, produces a spectrogram of power spectral density characterized by two peaks of variability - low frequency and high frequency (HF) - the latter of which is centered at the respiratory rate $[2,3]$. The recommendation of the Task Force [4] to use the range of 0.15 to $0.4 \mathrm{~Hz}$ (9 to 24 respirations per minute) to compute HRV in the HF band assumes that this range will include the respiratory rate, which is true in most clinical situations. However, in more extreme conditions, like heavy exercise, the actual respiratory rate may be out of this range, and therefore most studies on HRV during exercise used a range from 0.1 to 0.8 (or even 1) Hz to compute HRV in HF [5,6]. Likewise, patients undergoing weaning from mechanical ventilation can be tachypneic; the authors used a respiratory rate as high as 35 respirations per minute as a criterion for a failed spontaneous breathing trial (SBT), and such respiratory rates are obviously outside the range $(0.15$ to $0.4 \mathrm{~Hz})$ chosen to compute HF HRV. We suggest that, in patients failing an SBT or extubation, respiratory rate may increase and shift the HF peak of HRV toward the right of the spectrogram, above $0.4 \mathrm{~Hz}$, mistakenly decreasing the HF HRV if computed in the range of 0.15 to $0.4 \mathrm{~Hz}$. This might account for the lack of difference in HF HRV between successful/failed weaning, while a difference in total power was observed. I believe that future studies should take this methodological issue into consideration.
Abbreviations

HF: High frequency; HRV: Heart rate variability; SBT: Spontaneous breathing trial.

\section{Competing interests}

The author declares that he has no competing interests.

Published: 29 Apr 2014

\section{References}

1. Huang CT, Tsai YJ, Lin JW, Ruan SY, Wu HD, Yu CJ: Application of heart rate variability in patients undergoing weaning from mechanical ventilation. Crit Care 2014, 18:R21.

2. Pagani M, Lombardi F, Guzzetti S, Rimoldi O, Furlan R, Pizzinelli P, Sandrone $G$, Malfatto G, Dell'Orto S, Piccaluga E: Power spectral analysis of heart rate and arterial pressure variabilities as a marker of sympatho-vagal interaction in man and conscious dog. Circ Res 1986, 59:178-193.

3. Van de Louw A, Médigue $C_{\text {, }}$ Papelier $Y$, Cottin F: Breathing cardiovascular variability and baroreflex in mechanically ventilated patients. Am J Physiol Regul Integr Comp Physiol 2008, 295:R1934-R1940.

4. Heart rate variability: standards of measurement, physiological interpretation and clinical use. Task Force of the European Society of Cardiology and the North American Society of Pacing and Electrophysiology. Circulation 1996, 93:1043-1065.

5. Cottin F, Medigue C, Papelier Y: Effect of heavy exercise on spectral baroreflex sensitivity, heart rate, and blood pressure variability in welltrained humans. Am J Physiol Heart Circ Physiol 2008, 295:H1150-H1155.

6. Pichon AP, de Bisschop C, Roulaud M, Denjean A, Papelier Y: Spectral analysis of heart rate variability during exercise in trained subjects. Med Sci Sports Exerc 2004, 36:1702-1708.

\section{$10.1186 / \mathrm{cc} 13848$}

Cite this article as: Van de Louw: Heart rate variability analysis and weaning from mechanical ventilation: lessons from exercise physiology. Critical Care 2014, 18:426

Correspondence: avandelouw@hmc.psu.edu

Division of Pulmonary and Critical Care Medicine, Penn State Milton S Hershey Medical Center, 500 University Drive, Hershey, PA 17033, USA 